\title{
COMPARATIVE STUDY OF PHOSPHATE SOLUBILIZATION POTENTIAL OF TALAROMYCES PINOPHILUS STRAINS
}

\author{
MAJUMDER, M. S. I. ${ }^{1,2}$ - ISLAM, M. K. ${ }^{1,2,3}$ - AKAMINE, H. ${ }^{1,2}$ - SANO, A. ${ }^{1,2}$ - ONJO, M. ${ }^{1,4}$ - \\ HosSAIN, M. A. ${ }^{1,2^{*}}$ \\ ${ }^{I}$ The United Graduate School of Agricultural Sciences, Kagoshima University \\ Kagoshima 890-0065, Japan \\ ${ }^{2}$ Faculty of Agriculture, University of the Ryukyus, Okinawa 903-0213, Japan \\ ${ }^{3}$ Department of Soil Science, Faculty of Agriculture, Patuakhali Science and Technology \\ University, Bangladesh \\ ${ }^{4}$ Faculty of Agriculture, Kagoshima University, Kagoshima 890-0065, Japan \\ ${ }^{*}$ Corresponding author \\ e-mail: amzad@agr.u-ryukyu.ac.jp; phone: +81-98-895-8824; fax: +81-98-895-8741
}

(Received $24^{\text {th }}$ Jun 2019; accepted $16^{\text {th }}$ Oct 2019)

\begin{abstract}
Phosphorus (P) is one of the most essential macronutrients for plant growth and development. Most of the soils in the world contain insoluble $\mathrm{P}$ that cannot be utilized by the plants. Phosphate solubilizing fungi (PSF) including Talaromyces pinophilus possess more potential for providing available $\mathrm{P}$ in soil for plant nutrition. There is no report regarding $\mathrm{P}$ solubilization potential among the different strains of $T$. pinophilus. The article aimed to compare the Phosphorous solubilization capabilities of 17 Talaromyces pinophilus fungal strains, in order to determine the best options for environmentally friendly fertilizers. The $\mathrm{P}$ solubilization efficiency of the fungal strains was investigated in broth containing insoluble $\mathrm{Ca}_{3}\left(\mathrm{PO}_{4}\right)_{2}, \mathrm{AlPO}_{4}$ and $\mathrm{FePO}_{4}$ compounds. Result showed that $\mathrm{Ca}_{3}\left(\mathrm{PO}_{4}\right)_{2}$ was solubilized the most followed by $\mathrm{AlPO}_{4}$ and $\mathrm{FePO}_{4}$. The strains SI-17URAgr, NBRC 6345 and NBRC 100533 have strong abilities to solubilize $\mathrm{Ca}_{3}\left(\mathrm{PO}_{4}\right)_{2}$, but SI-19URAgr could solubilize both AlPO and $\mathrm{FePO}_{4}$. These results also imply that the strains SI-4URAgr and JCM 22801 have the potential to solubilize $\mathrm{AlPO}_{4}$ and $\mathrm{FePO}_{4}$, respectively. Although the $\mathrm{P}$ solubilization by different strains were source dependent, the strains SI-17URAgr, NBRC 6345 and NBRC 100533 were proved to be potential for solubilizing $\mathrm{P}$ from three sources tested. Solubilized $\mathrm{P}$ was negatively correlated with $\mathrm{pH}$ of the medium. This study suggested that these strains have a great potential as eco-friendly biofertilizers for sustainable soil management and crop production.
\end{abstract}

Keywords: fungal strain, phosphorus, insoluble phosphate, eco-friendly biofertilizers, sustainable soil management, soil $\mathrm{pH}$

\section{Introduction}

Phosphorus $(\mathrm{P})$ is the second most important limiting element required for plant growth and development (Chai et al., 2011; Ram et al., 2015). The soluble soil $\mathrm{P}$ concentration varies from 0.05 to $10 \mathrm{ppm}$, and more than $80 \%$ of the $\mathrm{P}$ becomes fixed and unavailable for absorption by plants due to adsorption, precipitation or conversion to organic forms (Holford, 1997). The fixed form of $\mathrm{P}$ in alkaline soils is tricalcium phosphate, $\mathrm{Ca}_{3}\left(\mathrm{PO}_{4}\right)_{2}$, whereas in acidic soils, it is mainly found as $\mathrm{FePO}_{4}$ and $\mathrm{AlPO}_{4}$ (Subba Rao, 1999).

The application of plant growth promoting microorganisms in agriculture could reduce the use of agrochemicals and support eco-friendly crop production (Herrera et al., 1993; Glick, 1995; Requena et al., 1997). It has been reported that a wide range of 
microorganisms, especially bacteria, solubilize insoluble phosphate (Badr El-Din et al., 1986; Gaind et al., 1991) although fungi are more efficient than bacteria (Venkateswarlu et al., 1984). A promising biotechnological strategy in the management of $\mathrm{P}$ fertilization is the use of phosphate-solubilizing fungi to solubilize rock phosphates and allow the recovery of unavailable $P$ fixed in the soil.

Talaromyces (Trichocomaceae) is an important fungal genus which is derived from the Greek word for 'basket', which capably describes the body in which ascospores are formed. In the past, species producing sexual stages with Penicillium anamorphs have been classified in Eupenicillium spp. and Talaromyces spp. After July 2011, species formally reclassifies as the Penicillium subgenus Biverticillium were classified in Talaromyces. The situation is complicated by the fact that many species now classified in Talaromyces will continue to be sought as Penicillium species in identifications (Pitt, 2014).

The habitats of Talaromyces pinophilus are global in environment, T. pinophilus (Samson et al., 2011); anamorph: Penicillium pinophilum (Thom, 1910) and P. allahabadense (Mehrotra et al., 1962) currently designated by T. allahabadensis (Samson et al., 2011) were prevalently isolated from soil, compost (El-Naggar et al., 2015), seeds grains (Ismail et al., 2016), phyllosphere (Lindow et al., 2002), phylloplane (Abdel-Hafez et al., 2015; Abdel-Gawad et al., 2017) and some medicinal plants (Koul et al., 2016; Yao et al., 2017).

T. pinophilus has received increasing attention in mycological research for its ability to act as a fungal antagonist and plant-growth promoter (Nicoletti et al., 2004; Pandey et al., 2008; Wani et al., 2016). A few categorical studies on phosphate solubilizing abilities of $T$. pinophilus were reported previously by others (Abdul Wahid and Mehana, 2000; Sembiring and Fauzi, 2017) but no studies have been made on the in-depth p-solubilization potential and comparative performance of different $T$. pinophilus strains yet. Therefore, the study aimed to compare the phosphorous solubilization capabilities of $17 \mathrm{~T}$. pinophilus fungal strains, in order to determine the best options for environmentally friendly fertilizers.

\section{Materials and Methods}

\section{Fungal Isolates and Culture Preparation}

The study was carried out in the Mycology Laboratory, Faculty of Agriculture, University of the Ryukyus, Okinawa, Japan during September 2017- March 2019 under a class II biohazard cabinet (BHC-1306IIA/3B, AIRTECH, Tokyo, Japan) followed to the biosafety classification by National Institute of Infectious Disease of Japan, because of possibilities including toxic fungal species treated as BSL2 during the working tenure. Seventeen $T$. pinophilus fungal strains were used in this study where 4 strains isolated from subtropical soils in Okinawa, Japan and 13 strains collected from different institutions in Japan (Table 1). The isolates were cultured on potato dextrose agar (PDA; Becton, Dickinson and Company, Sparks, MD, USA) slant at room temperature $\left(25^{\circ} \mathrm{C}\right)$ for further study.

\section{Morphological Studies}

Morphological studies were done according to the method (Watanabe, 2010). Pigment exudation were investigated on PDA slants. High-temperature resistance and 
pathogenic potential of the isolates were examined. The isolates were cultured on PDA slants in duplicate and incubated at $35^{\circ} \mathrm{C}, 37^{\circ} \mathrm{C}$ and $42^{\circ} \mathrm{C}$ for 7 days to evaluate the growth of mycelia. Growth of isolates at $25^{\circ} \mathrm{C}$ (room temperature) treated as positive control.

\section{Preparation of Spore Suspension}

Sporulated pure fungal cultured slants were selected for preparation of spore suspension followed by standard procedure. A total volume of $5 \mathrm{ml}$ sterile water with $0.02 \%$ of tween 80 (Polyoxyethylene sorbitan monooleate, Nacalai Tesque, Inc, Kyoto, Japan) was poured on the culture slants and the fungal colony surface was lightly scraped by a sterile inoculation loop (Thermo Scientific ${ }^{\mathrm{TM}}$, Nunc ${ }^{\mathrm{TM}}$ Disposable Loops and Needles, Thermo Scientific ${ }^{\mathrm{TM}}$ 251586, Fisher Scientific, Tokyo, Japan). The cultures were passing through a syringe with a $4 \times 4 \mathrm{~cm}$ sheet of a sterile absorbent cotton (Kyualet, Kawamoto Sangyo, Osaka, Japan). Spore count was done by a hemocytometer and the suspension was adjusted to approximately $10^{6}$ spores $\mathrm{mL}^{-1}$.

Table 1. List of the fungal strains used in the study

\begin{tabular}{c|c|c|c|c|c}
\hline Isolates & $\begin{array}{c}\text { Strain in } \\
\text { GenBank }\end{array}$ & Source & Country of origin & Fungi & Institution \\
\hline 1 & SI-4URAgr & Soil & Japan & Talaromyces pinophilus & Univ. Ryukyus \\
2 & SI-15URAgr & Soil & Japan & Talaromyces pinophilus & Univ. Ryukyus \\
3 & SI-17URAgr & Soil & Japan & Talaromyces pinophilus & Univ. Ryukyus \\
4 & SI-19URAgr & Soil & Japan & Talaromyces pinophilus & Univ. Ryukyus \\
5 & IFM 64651 & Sputum & Japan & Penicillium pinophilum & Chiba University \\
6 & IFM 57309 & Sputum & Japan & Penicillium pinophilum & Chiba University \\
7 & NBRC 6345 & Radio set & Papua New Guinea & Talaromyces pinophilus & NITE BRC \\
8 & NBRC 100533 & Polyvinyl chloride plastic & France & Talaromyces pinophilus & NITE BRC \\
9 & NBRC 33285 & Polyvinyl chloride plastic & France & Talaromyces pinophilus & NITE BRC \\
10 & NBRC 106907 & Soil & Japan & Penicillium pinophilum & NITE BRC \\
11 & NBRC 9575 & Polyvinyl chloride plastic & France & Penicillium allahabadense & NITE BRC \\
12 & JCM 9928 & Soil & India & Penicillium pinophilum & RIKEN \\
13 & JCM 5593 & Radio set & Papua New Guinea & Penicillium pinophilum & RIKEN \\
14 & JCM 22801 & Wood stakes & Australia & Penicillium pinophilum & RIKEN \\
15 & JCM 22802 & Barley grain & Australia & Penicillium pinophilum & RIKEN \\
16 & JCM 22803 & Moldy sorghum grain & Australia & Penicillium pinophilum & RIKEN \\
17 & JCM 23043 & Radio set & Papua New Guinea & Penicillium pinophilum & RIKEN \\
\hline
\end{tabular}

NITE; National Institute of Technology and Evaluation, Biological Resource Center, NITE (NBRC), Japan. RIKEN; is a large scientific research institute in Japan

\section{Determination of TCP Solubilization Index on Solid Medium}

All the isolates were tested under in vitro condition for their phosphate solubilization activity on Pikovskaya's agar medium containing $0.5 \%$ tricalcium phosphate (TSP) as an insoluble phosphorus source. A spot inoculation of each fungal isolate was made onto the plates in triplicate under aseptic condition and incubated at $28^{\circ} \mathrm{C}$ for 7 days in darkness. At $7^{\text {th }}$ day of incubation, phosphate solubilization index was measured using the following formula (Premono et al., 1996): 


\section{Quantitative Estimation of Phosphate Solubilization}

It was carried out using Erlenmeyer flask containing $40 \mathrm{ml}$ Pikovskaya's broth medium supplemented with $0.5 \%$ tricalcium phosphate $\left[\mathrm{Ca}_{3}\left(\mathrm{PO}_{4}\right)_{2}\right]$, aluminium phosphate $\left(\mathrm{AlPO}_{4}\right)$ and iron phosphate $\left(\mathrm{FePO}_{4}\right)$. After sterilization, the medium of each flask was inoculated with the $5 \%(\mathrm{v} / \mathrm{v})$ spore suspension of a particular fungal isolate containing $10^{6}$ spores $\mathrm{mL}^{-1}$. Sterile distilled water inoculated flaks were treated as control. Three replicates were maintained for each test isolate and mean value was recorded. Incubation was done at $25^{\circ} \mathrm{C}$ in an incubator shaker (EYELA Multi Shaker MMS-3010) at $120 \mathrm{rpm}$ for 9 days. The samples were autoclaved and centrifuged (TOMY MX-301) at $5000 \mathrm{rpm}$ for 25 minutes to remove any suspended solids and mycelial parts. Then the cultures were filtered through $0.45 \mu \mathrm{m}$ pore size syringe filter unit (Advantech, Japan). The filtrates were used for analysis of soluble phosphate and $\mathrm{pH}$ value. The $\mathrm{pH}$ value of the culture supernatants was determined by a $\mathrm{pH}$ meter (HORIBA, Japan) equipped with a glass electrode. The amount of soluble phosphorus in culture supernatants was measured by molybdenum blue method (Murphy and Riley, 1962) and expressed as mg/L. Samples cultured for 3, 6 and 9 days were compared. After calculation of mean phosphate degradation ability from 17 isolates of each day, we selected the adequate period for the comparison depending on the substrate.

\section{Data Analysis}

All experiments were conducted in triplicate and data were analyzed using Microsoft Excel program. The mean values were compared by Fisher test and significant differences were detected at $p<0.05$ level. Correlation between solubilized phosphate and $\mathrm{pH}$ of the medium was determined by using Pearson correlation studies.

\section{Results}

\section{Pigment Exudation}

All isolates were reconfirmed based on morphological studies. Morphological studies results are not shown. The isolates produced various colour in PDA slant, such as coffee, orange, yellow and cream (Fig. 1). Differential colour formation by T. pinophilus isolates might be attributed to the presence of bioactive metabolites.

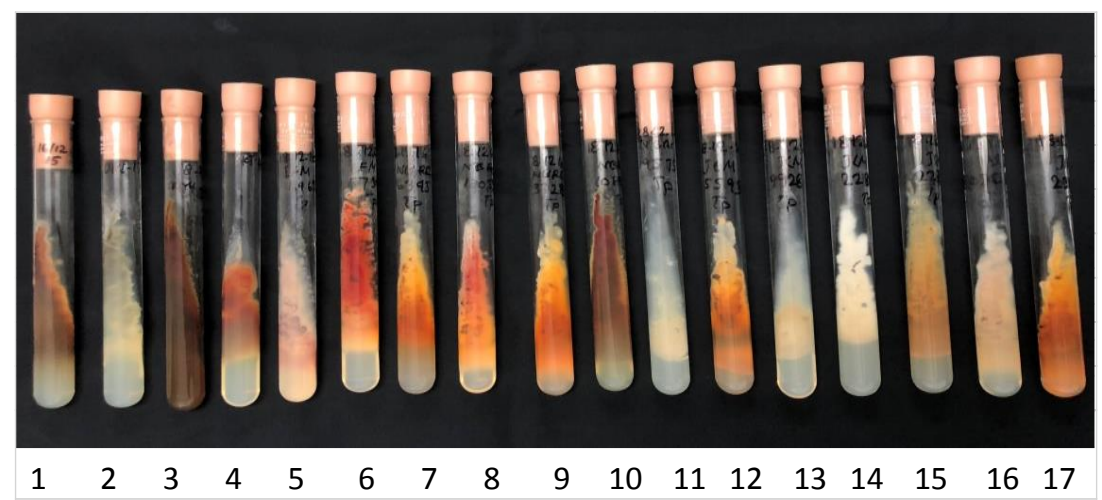

Figure 1. Talaromyces pinophilus isolates grown on Potato Dextrose Agar (PDA) slant for 7 days at 25 C [Coffee: 1, 3, 10; Cream: 2, 5, 11, 13, 14, 16; Orange: 4, 6; Yellow=7, $8,9,12,15,17]$ 


\section{Qualitative Phosphate Solubilization}

All isolates showed different levels of phosphate solubilization from inconspicuous to a substantial in Pikovskaya's agar medium using tricalcium phosphate as the substrate. Six isolates produced clear zone, 5 developed translucent and the remaining isolates had inconspicuous zones. All isolates also showed significant phosphate solubilization in Pikovskaya's agar medium using tricalcium phosphate as the substrate. The phosphate solubilization index (PSI) ranged from 1.05 to 1.46 (Table 2).

Table 2. TCP solubilization in Pikovskaya's agar by 17 fungal strains

\begin{tabular}{c|c|c|c|c}
\hline Isolate & Fungal strain & Fungi & PSI & Type of zone \\
\hline 1 & SI-4URAgr & Talaromyces pinophilus & $1.31 \pm 0.01^{\mathrm{b}}$ & $\mathrm{C}$ \\
2 & SI-15URAgr & Talaromyces pinophilus & $1.46 \pm 0.03^{\mathrm{a}}$ & $\mathrm{C}$ \\
3 & SI-17URAgr & Talaromyces pinophilus & $1.09 \pm 0.01^{\mathrm{d}}$ & $\mathrm{T}$ \\
4 & SI-19URAgr & Talaromyces pinophilus & $1.12 \pm 0.01^{\mathrm{d}}$ & $\mathrm{T}$ \\
5 & IFM 64651 & Penicillium pinophilum & $1.07 \pm 0.02^{\mathrm{d}}$ & $\mathrm{I}$ \\
6 & IFM 57309 & Penicillium pinophilum & $1.09 \pm 0.03^{\mathrm{d}}$ & $\mathrm{I}$ \\
7 & NBRC 6345 & Talaromyces pinophilus & $1.11 \pm 0.02^{\mathrm{d}}$ & $\mathrm{T}$ \\
8 & NBRC100533 & Talaromyces pinophilus & $1.21 \pm 0.08^{\mathrm{bc}}$ & $\mathrm{C}$ \\
9 & NBRC33285 & Talaromyces pinophilus & $1.14 \pm 0.08^{\mathrm{cd}}$ & $\mathrm{C}$ \\
10 & NBRC 106907 & Penicillium pinophilum & $1.24 \pm 0.03^{\mathrm{b}}$ & $\mathrm{T}$ \\
11 & NBRC 9575 & Penicillium allahabadense & $1.07 \pm 0.03^{\mathrm{d}}$ & $\mathrm{I}$ \\
12 & JCM 9928 & Penicillium pinophilum & $1.09 \pm 0.06^{\mathrm{d}}$ & $\mathrm{T}$ \\
13 & JCM 5593 & Penicillium pinophilum & $1.19 \pm 0.09^{\mathrm{bc}}$ & $\mathrm{C}$ \\
14 & JCM 22801 & Penicillium pinophilum & $1.05 \pm 0.05^{\mathrm{d}}$ & $\mathrm{I}$ \\
15 & JCM 22802 & Penicillium pinophilum & $1.08 \pm 0.05^{\mathrm{d}}$ & $\mathrm{I}$ \\
16 & JCM 22803 & Penicillium pinophilum & $1.09 \pm 0.05^{\mathrm{d}}$ & $\mathrm{T}$ \\
17 & JCM 23043 & Penicillium pinophilum & $1.06 \pm 0.05^{\mathrm{d}}$ & $\mathrm{I}$ \\
\hline
\end{tabular}

PSI: Phosphate solubilization index, Values given are the mean \pm standard deviation of three independent replicates, Same letter in the column are not significantly different at $\mathrm{p}<0.05$ by Fisher's test, $\mathrm{C}=\mathrm{clear}, \mathrm{T}=$ translucent, $\mathrm{I}=$ inconspicuous

\section{Quantitative Phosphate Solubilization}

Phosphate solubilization by all isolates were tested in Pikovskaya's broth medium using three substrates of recalcitrant phosphate compounds: tricalcium phosphate $\mathrm{Ca}_{3}\left(\mathrm{PO}_{4}\right)_{2}$, aluminium phosphate $\left(\mathrm{AlPO}_{4}\right)$ and iron phosphate $\left(\mathrm{FePO}_{4}\right)$. The phosphate solubilizing ability of fungal isolates varied with incubation period and substrates. The best period of observation was 6 days considering their mean $\mathrm{P}$ solubilization for the three substrates (Table 3).

All $T$. pinophilus strains were tested for their ability to solubilize hardly soluble phosphate sources $\left[\mathrm{Ca}_{3}\left(\mathrm{PO}_{4}\right)_{2}, \mathrm{AlPO}_{4}\right.$, and $\left.\mathrm{FePO}_{4}\right]$. All of the T. pinophilus strains showed potential $\mathrm{P}$ solubilizing in the medium containing $\mathrm{Ca}_{3}\left(\mathrm{PO}_{4}\right)_{2}$ followed by $\mathrm{AlPO}_{4}$ and $\mathrm{FePO}_{4}$ (Table 4). The solubilized $\mathrm{P}$ ranged between 83.7-574.8 $\mathrm{mgL}^{-1}$, 50.5-192.4 mgL $\mathrm{md}^{-1}$ and 50.5-192.4 $\mathrm{mgL}^{-1}$ from $\mathrm{Ca}_{3}\left(\mathrm{PO}_{4}\right)_{2}, \mathrm{AlPO}_{4}$, and $\mathrm{FePO}_{4}$, respectively. Among 17 isolates, 6 isolates (SI-4URAgr, SI-17URAgr, SI-19URAgr, NBRC 6345, NBRC 100533 and JCM 22801) were considered as outstanding isolates because solubilized $\mathrm{P}$ was higher than the sum of the mean and standard deviation of $\mathrm{P}$ solubilized by 17 isolates. The highest amount of $\mathrm{P}$ solubilization from $\mathrm{Ca}_{3}\left(\mathrm{PO}_{4}\right)_{2}$ was shown in NBRC6345 (574.8 $\left.\mathrm{mgL}^{-1}\right)$ followed by NBRC100533 (540.4 $\left.\mathrm{mgL}^{-1}\right)$ and SI-17URAgr $\left(537.2 \mathrm{mgL}^{-1}\right)$. The highest amount of $\mathrm{P}$ solubilization from AlPO 
shown in SI-4URAgr (192.4 $\left.\mathrm{mgL}^{-1}\right)$ followed by SI-19 (153.7 $\left.\mathrm{mgL}^{-1}\right)$. The highest amount of $\mathrm{P}$ solubilization from $\mathrm{FePO}_{4}$ was shown in SI-19URAgr $\left(145.2 \mathrm{mgL}^{-1}\right)$ followed by JCM $22801\left(126.1 \mathrm{mgL}^{-1}\right)$. The strain SI-19URAgr showed outstanding performance in both $\mathrm{AlPO}_{4}$, and $\mathrm{FePO}_{4}$ solubilization (Table 4). In case of total solubilized phosphate $\left(\mathrm{mgL}^{-1}\right)$ from three substrates (TCP, AL-P and Fe-P), the highest amount of $\mathrm{P}$ solubilization was shown in NBRC $6345\left(829.6 \mathrm{mgL}^{-1}\right)$ followed by SI-17URAgr (789.2 $\left.\mathrm{mgL}^{-1}\right)$ and NBRC100533 (770.4 $\left.\mathrm{mgL}^{-1}\right)$. The tested isolates produced various colours in broth medium using three $\mathrm{P}$ substrates during incubation period (data not shown).

Table 3. Selection for the best period of phosphate solubilization by 17 isolates

\begin{tabular}{c|c|c|c|c|c|c|c|c}
\hline \multicolumn{9}{c}{ Solubilized phosphate $(\mathbf{m g} / \mathbf{L})$} \\
\hline \multicolumn{3}{c|}{ TCP } & \multicolumn{3}{c}{ Al-P } & \multicolumn{3}{c}{ Fe-P } \\
\hline 3 days & 6 days & 9 days & 3 days & 6 days & 9 days & 3 days & 6 days & 9 days \\
\hline $196.2 \pm 93.0$ & $354.3 \pm 136.1^{*}$ & $343.2 \pm 125.1$ & $80.6 \pm 29.8$ & $111.6 \pm 40.7^{*}$ & $63.6 \pm 22.2$ & $55.3 \pm 16.3$ & $95.8 \pm 28.1^{*}$ & $69.4 \pm 20.1$ \\
\hline
\end{tabular}

TCP: tricalcium phosphate, Al-P: aluminium phosphate, Fe-P: iron phosphate, Values given are the mean \pm standard deviation of $\mathrm{P}$ solubilized by 17 fungal isolates, An asterisk (*) indicated the best period of phosphate solubilization

Table 4. Phosphate solubilization from different substrates by T. pinophilus fungal strains

\begin{tabular}{c|c|c|c|c|c|c}
\hline \multirow{2}{*}{ Sl. No } & \multirow{2}{*}{ Strain } & \multirow{2}{*}{ Fungi } & \multicolumn{2}{|c|}{ Solubilized phosphate (mg/L) } & \multirow{2}{*}{ Total P } \\
\cline { 4 - 6 } & & TCP & AL-P & Fe-P & (mo/L) \\
\hline 1 & SI-4URAgr & Talaromyces pinophilus & 268.4 & $192.4^{*}$ & 46.5 & 507.3 \\
2 & SI-15URAgr & Talaromyces pinophilus & 363.7 & 132.9 & 34.8 & 531.4 \\
3 & SI-17URAgr & Talaromyces pinophilus & $537.2^{*}$ & 135.7 & 116.3 & $789.2^{*}$ \\
4 & SI-19URAgr & Talaromyces pinophilus & 314.0 & $153.7 *$ & $145.2^{*}$ & 612.8 \\
5 & IFM 64651 & Penicillium pinophilum & 324.3 & 50.5 & 85.6 & 460.5 \\
6 & IFM 57309 & Penicillium pinophilum & 228.5 & 51.4 & 65.6 & 345.5 \\
7 & NBRC 6345 & Talaromyces pinophilus & $574.8^{*}$ & 148.6 & 106.2 & $829.6^{*}$ \\
8 & NBRC100533 & Talaromyces pinophilus & $540.4 *$ & 134.7 & 95.3 & $770.4^{*}$ \\
9 & NBRC 33285 & Talaromyces pinophilus & 263.5 & 135.8 & 95.4 & 494.7 \\
10 & NBRC106907 & Penicillium pinophilum & 482.5 & 107.2 & 106.5 & 696.3 \\
11 & NBRC 9575 & Penicillium allahabadense & 83.7 & 96.0 & 116.5 & 296.2 \\
12 & JCM 9928 & Penicillium pinophilum & 135.2 & 85.1 & 105.3 & 325.6 \\
13 & JCM 5593 & Penicillium pinophilum & 387.7 & 137.2 & 105.3 & 630.2 \\
14 & JCM 22801 & Penicillium pinophilum & 405.7 & 54.8 & $126.1 *$ & 586.6 \\
15 & JCM 22802 & Penicillium pinophilum & 392.2 & 83.9 & 85.9 & 562.1 \\
16 & JCM 22803 & Penicillium pinophilum & 397.1 & 125.2 & 116.1 & 638.4 \\
17 & JCM 23043 & Penicillium pinophilum & 325.2 & 71.7 & 76.6 & 473.5 \\
\hline
\end{tabular}

TCP: tricalcium phosphate, Al-P: aluminium phosphate, Fe-P: iron phosphate, Values given are the mean \pm standard deviation of $\mathrm{P}$ solubilized by 17 fungal isolates, An asterisk (*) indicated outstanding values of solubilized phosphate, It was higher than sum of mean and standard deviation of P solubilized by 17 fungal isolates

\section{Correlation Between $\mathrm{pH}$ and Soluble P}

The $\mathrm{pH}$ of the culture medium exhibited the opposite changes. It decreased with the increased amount of soluble $\mathrm{P}$ in the medium. Correlation studies showed a significant inverse relationship between soluble $\mathrm{P}$ and $\mathrm{pH}$ of the culture medium (Fig. 2A, 2B, 2C). 
The negative correlation was observed in all fermented broth culture and correlation coefficient (r) was $-0.88,-0.51$ and -0.60 in TCP, Al-P and Fe-P, respectively. The strong negative correlation was observed in TCP containing medium.
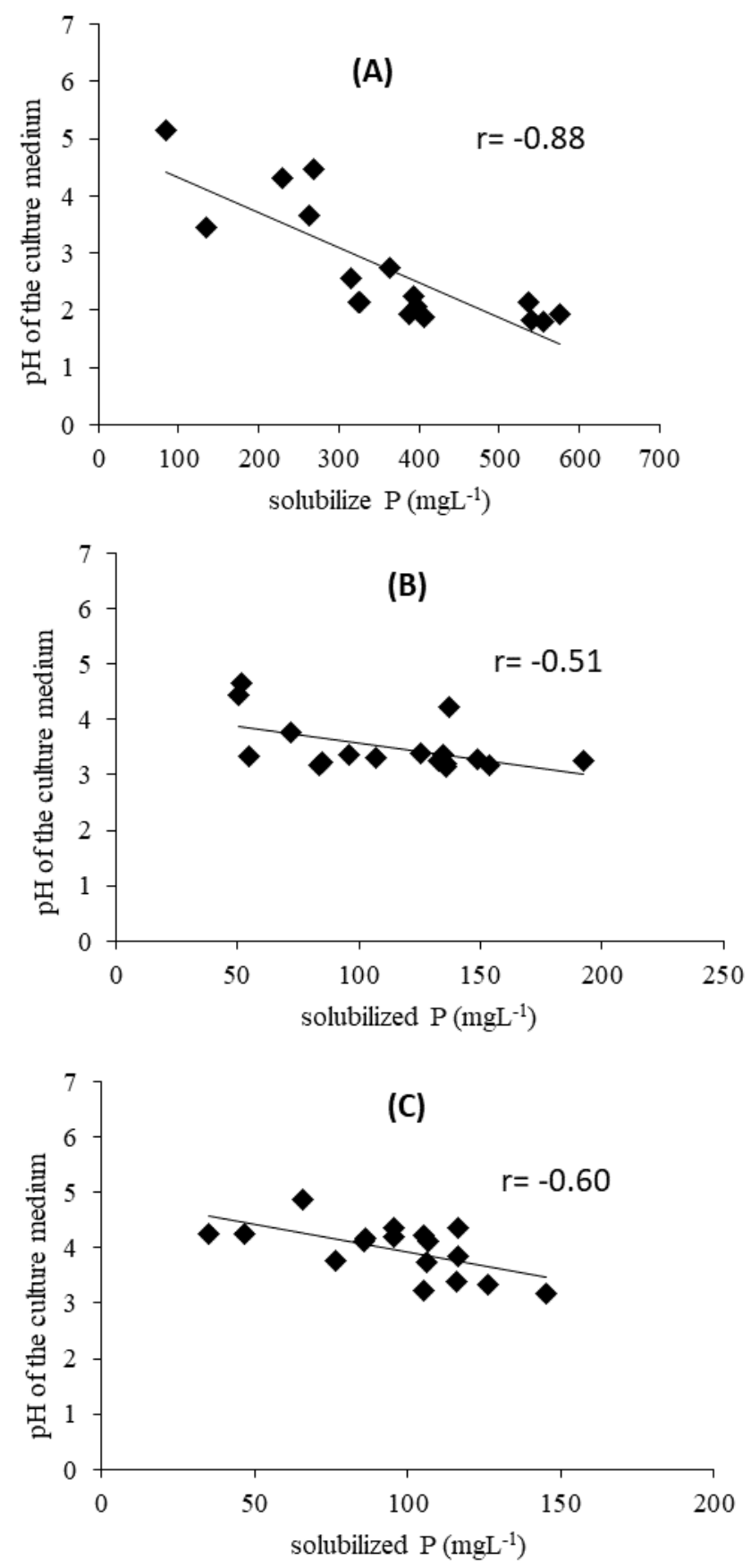

Figure 2. Pearson's correlation between soluble phosphate and $p H$ of the culture medium supplemented with TCP (2A), AlPO $\mathrm{O}_{4}(2 \mathrm{~B})$ and $\mathrm{FePO}_{4}(2 \mathrm{C})$; inoculated by 17 fungal strains. [SI4URAgr, SI-15URAgr, SI-17URAgr, SI-19URAgr, IFM 64651, IFM 57309, NBRC 6345, NBRC 100533, NBRC 33285, NBRC 106907, NBRC 9575, JCM 9928, JCM 5593, JCM 22801, JCM 22802, JCM 22803, JCM 23043] 


\section{Temperature Effects on Strains}

Survival of the strains at different temperature was investigated (Table 5). Most of the strains could grow and survive at $25^{\circ} \mathrm{C}-37^{\circ} \mathrm{C}$. Strain SI-4URAgr, SI-15URAgr, SI-17URAgr, SI-19URAgr and NBRC 106907 could grow at $25^{\circ} \mathrm{C}-42^{\circ} \mathrm{C}$. These strains are summer tolerant and they could survive both acidic (low $\mathrm{pH}$ ) and alkaline environment (high $\mathrm{pH}$ ).

Table 5. The growth and survival of T pinophilus strains at different temperature

\begin{tabular}{|c|c|c|c|c|c|c|}
\hline \multirow{2}{*}{ SL No. } & \multirow{2}{*}{ Strain } & \multirow{2}{*}{ Fungi } & \multicolumn{4}{|c|}{ Growth temperature } \\
\hline & & & $25^{\circ} \mathrm{C}$ & $35^{\circ} \mathrm{C}$ & $37^{0} \mathrm{C}$ & $42^{0} \mathrm{C}$ \\
\hline 1 & SI-4URAgr & Talaromyces pinophilus & + & + & + & + \\
\hline 2 & SI-15URAgr & Talaromyces pinophilus & + & + & + & + \\
\hline 3 & SI-17URAgr & Talaromyces pinophilus & + & + & + & + \\
\hline 4 & SI-19URAgr & Talaromyces pinophilus & + & + & + & + \\
\hline 5 & IFM 64651 & Penicillium pinophilum & + & + & + & - \\
\hline 6 & IFM 57309 & Penicillium pinophilum & + & + & + & - \\
\hline 7 & NBRC 6345 & Talaromyces pinophilus & + & + & + & - \\
\hline 8 & NBRC100533 & Talaromyces pinophilus & + & + & + & - \\
\hline 9 & NBRC 33285 & Talaromyces pinophilus & + & + & + & - \\
\hline 10 & NBRC106907 & Penicillium pinophilum & + & + & + & + \\
\hline 11 & NBRC 9575 & Penicillium allahabadense & + & + & + & - \\
\hline 12 & JCM 9928 & Penicillium pinophilum & + & + & + & - \\
\hline 13 & JCM 5593 & Penicillium pinophilum & + & + & + & - \\
\hline 14 & JCM 22801 & Penicillium pinophilum & + & + & + & - \\
\hline 15 & JCM 22802 & Penicillium pinophilum & + & + & + & - \\
\hline 16 & JCM 22803 & Penicillium pinophilum & + & + & + & - \\
\hline 17 & JCM 23043 & Penicillium pinophilum & + & + & + & - \\
\hline
\end{tabular}

(+) indicated growth of fungi, (-) indicated no growth.

\section{Discussion}

Morphological studies reconfirmed that all the 17 strains used in this study belong to Talaromyces pinophilus. All fungal isolates produced different colours in the medium regardless of the $\mathrm{P}$ substrates, but the colour seemed not to have any relation with $\mathrm{P}$ solubilization.

T. pinophilus has various applications based on the production of enzymes (Hansen et al., 2015; Li et al., 2017) as well as a renewable source of pigments, colorants (Caro et al., 2017) and bioactive compounds (Wang et al., 2013; Nicoletti et al., 2016) and degrading ability of agricultural waste (El-Naggar et al., 2015). T. pinophilus is able to produce a variety of bioactive metabolites, including alkaloids, peptides, lactones, polyketides and miscellaneous structure type compounds, with different chemical and biological activities. T. pinophilus produces biomass-degrading enzymes such as $\alpha$-amylase (Xian et al., 2015), cellulase (Visser et al., 2013), endoglucanase (Pol et al., 2012), xylanase (Visser et al., 2013), laccase (Dhakar et al., 2014) and $\alpha$-galactosidase (Visser et al., 2013). T. pinophilus produces a variety of medically useful metabolites such as 3-O- methylfunicone, which is used to inhibit mesothelioma cell motility, and talaromycolides 1-3,5 and 11 which inhibit the growth of the human pathogen methicillin resistant Staphylococcus aureus (Buommino et al., 2012).

In the present study, all isolates showed better $\mathrm{P}$ solubilizing activity in liquid medium compared with solid medium. The possible reason for these anomalous behaviors of isolates on liquid and solid media could be attributed to nutrient availability, varying diffusion rate of different organic acids secreted by fungi, and growth requirement of fungi (Jain et al., 2014). 
Alam et al. (2002) reported that some isolates having little clear zone on solid agar medium exhibited higher phosphate solubilization efficiency in liquid medium. Some fungal isolates showed larger clear zones on solid agar medium but low phosphate solubilization in liquid medium. This shows that higher PSI on solid agar medium does not necessarily show solubilization efficiency in liquid medium. Thus, the plate technique is insufficient to screen the best $\mathrm{P}$ solubilizers and to detect all phosphate solubilizers mentioned by Nautiyal (1999).

The strongest $\mathrm{P}$ solubilization was found in $\mathrm{Ca}_{3}\left(\mathrm{PO}_{4}\right)_{2}$ followed by $\mathrm{AlPO}_{4}$ and $\mathrm{FePO}_{4}$ because $\mathrm{AlPO}_{4}$ and $\mathrm{FePO}_{4}$ have complex structure than $\mathrm{Ca}_{3}\left(\mathrm{PO}_{4}\right)_{2}$ while fungi exhibited low $\mathrm{P}$ solubilizing ability in media containing $\mathrm{AlPO}_{4}$ and $\mathrm{FePO}_{4}$ (Son et al., 2006; Zhang et al., 2018). The mechanisms of phosphate solubilization by microorganisms are very complex and are not completely known yet. The very common mechanisms are acidification, chelation and exchange reactions (Chai et al., 2011). Organic acids play an important role in phosphate solubilization processes, which can help the release of $\mathrm{P}$ by providing protons and complexing anions, or ligand exchange reactions or complexion of metal ions release to solution. Organic acids production depends on the interaction of $\mathrm{P}$ source and fungi (Scervino et al., 2013; Zhang et al., 2018).

In the present study, the isolates (SI-4URAgr, SI-17URAgr, SI-19URAgr, NBRC 6345, NBRC 100533, and JCM 22801) showed the highest efficiency in P solubilization by decreasing $\mathrm{pH}$ of the culture medium, which indicated higher amount of organic acid production. Solubilization of the different $\mathrm{P}$ sources mostly depended on the amount of organic acids production by fungi (Zhang et al., 2018). Tricarboxylic acids and other lower molecular weight organic acids are considered to be the main contributors to phosphate solubilization and a decrease in $\mathrm{pH}$ of the medium (Chai et al., 2011).

It was observed that phosphate solubilization was negatively correlated with $\mathrm{pH}$ of the medium. There are several reports where such correlation was documented (Pandey et al., 2008; Jain et al., 2012; Wani et al., 2016). The activities in lower $\mathrm{pH}$ indicated that the increase of organic acids in the medium (Pradhan and Sukla, 2005; Saxena et al., 2013). However, soluble $\mathrm{P}$ was increased without changing $\mathrm{pH}$ in some occasion because of other mechanism (Jain et al., 2012, 2017) such as; chelation and exchange reactions (Chai et al., 2011).

\section{Conclusions}

The article aimed to compare the phosphorous solubilization capabilities of 17 Talaromyces pinophilus fungal strains, in order to determine the best options for environmentally friendly fertilizers. Findings showed that $\mathrm{Ca}_{3}\left(\mathrm{PO}_{4}\right)_{2}$ was solubilized the most followed by $\mathrm{AlPO}_{4}$ and $\mathrm{FePO}_{4}$. Among the strains tested SI-17URAgr, NBRC 6345 and NBRC100533 were potential for $\mathrm{Ca}_{3}\left(\mathrm{PO}_{4}\right)_{2}$ solubilization but SI-19URAgr could solubilize both $\mathrm{AlPO}_{4}$ and $\mathrm{FePO}_{4}$ whereas SI-4URAgr and JCM 22801 were potential for solubilization of Al-P and Fe-P, respectively. Overall findings suggest that the strains SI-17URAgr, NBRC 6345 and NBRC 100533 could be potent for solubilizing $\mathrm{P}$ from different sources. Thus these strains might be used as inoculant in the soil containing various inorganic P. However, further trials are needed to determine the capability of these strains for $\mathrm{P}$ solubilization in field experiment, sustainable soil management as well as crop production.

Acknowledgments. We are grateful to Instrumental Research Center (IRC), University of the Ryukyus, Japan for analytical support to this study. 


\section{REFERENCES}

[1] Abdel-Gawad, K. M., Abdel-Mallek, A. Y., Hussein, N. A., Abdel-Rahim, I. R. (2017): Diversity of mycobiota associated with onion (Allium cepa L.) cultivated in Assiut, with a newly recorded fungal species to Egypt. - J Microbiol Biotech Food Sci 6(5): 1145-1151.

[2] Abdel-Hafez, S. I. I., Abo-Elyousr, K. A., Abdel-Rahim, I. R. (2015): Leaf surface and endophytic fungi associated with onion leaves and their antagonistic activity against Alternaria porri. - Czech Mycol. 67(1): 1-22.

[3] Abdul Wahid, O. A., Mehana, T. A. (2000): Impact of phosphate-solubilizing fungi on the yield and phosphorus-uptake by wheat and faba bean plants. - Microbiol Res. 155(3): 221-227.

[4] Alam, S., Khalil, S., Ayub, N., Rashid, M. (2002): In vitro solubilization of inorganic phosphate by Phosphate Solubilizing Microorganisms (PSM) from Maize Rhizosphere. International Journal of Agriculture \& Biology 4: 454-458.

[5] Badr El-Din, S. M. S., Khalafallah, M. A., Moawad, H. (1986): Response of soybean to dual inoculation with Rhizobium japanicum and phosphate dissolving bacteria. - Z Pflanzenemaehr. Bodenk. 149: 130-135.

[6] Buommino, E., De Filippis, A., Nicoletti. R., Menegozzo, M., Menegozzo, S., Ciavatta, M. L., Rizzo, A., Brancato, V., Tufano, M. A., Donnarumma, G. (2012): Cell-growth and migration inhibition of human mesothelioma cells induced by 3-O-Methylfunicone from Penicillium pinophilum and cisplatin. - Invest New Drug. 30: 1343-1351.

[7] Caro, Y., Venkatachalam, M., Lebeau, J., Fouillaud, M., Dufosse, L. (2017): Pigments and colorants from filamentous fungi. - In: Mérillon, J.-M., Ramawat, K. G. (eds.) Fungal Metabolites. Springer International Publishing, Cham.: 499-568.

[8] Chai, B., Yan, W., Pengming, L., Biao, L., Meiying, G. (2011): Isolation and phosphate solubilizing ability of a fungus, Penicillium sp. from soil of alum mine. - JBM 51: 5-14.

[9] Dhakar, K., Jain, R., Tamta, S., Pandey, A. (2014): Prolonged laccase production by a cold and $\mathrm{pH}$ tolerant strain of Penicillium pinophilum (MCC 1049) isolated from a low temperature environment. - Enzyme Res.: 120708.

[10] El-Naggar, N. E. A., Haroun, S. A., Owais, E. A., Sherief, A. A. (2015): Identification of newly isolated Talaromyces pinophilus and statistical optimization of ( $\beta$-glucosidase production under solid-state fermentation. - Preparative Biochemistry \& Biotechnology 45: 712-729.

[11] Gaind, S., Gaur, A. C. (1991): Thermotolerant phosphate solubilizing microorganisms and their interaction with mung bean. - Plant Soil 133: 141-149.

[12] Glick, B. R. (1995): The enhancement of plant growth by free-living bacteria. - Can. J. Microbiol. 41(2): 109-117.

[13] Hansen, G. H., Lübeck, M., Frisvad, J. C., Lübeck, P. S., Andersen, B. (2015): Production of cellulolytic enzymes from ascomycetes: Comparison of solid state and submerged fermentation. - Process Biochem. 50: 1327-1341.

[14] Herrera, M. A., Salamanka, C. P., Barea, J. M. (1993): Inoculation of woody legumes with selected arbuscular mycorrhizal fungi and rhizobia to recover desertified Mediterranean ecosystems. - App. Env. Microbiol. 59: 129-133.

[15] Holford, I. C. R. (1997): Soil phosphorus: its measurement, and its uptake by plants. Aust. J. Soil Res. 35(2): 227-240.

[16] Ismail, M. A., El-Maali, N. T. A., Omran, G., Nasser, N. M. (2016): Biodiversity of mycobiota in peanut seeds, corn and wheat grains with special reference to their aflatoxigenic ability. - J. Microbiol. Biotechnol. Food Sci. 5: 314.

[17] Jain, R., Saxena, J., Sharma, V. (2012): Solubilization of inorganic phosphates by Aspergillus awamori S19 isolated from agricultural soil of semi-arid region. - Annals Microbiol. 62: 725-735. 
[18] Jain, R., Saxena, J., Sharma, V. (2014): Differential effects of immobilized and free forms of phosphate solubilizing fungal strains on the growth and $\mathrm{P}$ uptake of mungbean plants. - Annals Microbiol. 64: 1523-1534.

[19] Jain, R., Saxena, J., Sharma, V. (2017): The ability of two fungi to dissolve hardly soluble phosphates in solution. - Mycology 8(2): 104-110.

[20] Koul, M., Meena, S., Kumar, A., Sharma, P. R., Singamaneni, V., Riyaz-Ul Hassan, S., Hamid, A., Chaubey, A., Prabhakar, A., Gupta, P. (2016): Secondary metabolites from endophytic fungus Penicillium pinophilum induce ROS-mediated apoptosis through mitochondrial pathway in pancreatic cancer cells. - Planta Med. 82(4): 344-355.

[21] Li, C. X., Zhao, S., Zhang, T., Xian, L., Liao, L. S., Liu, J. L., Feng, J. X. (2017): Genome sequencing and analysis of Talaromyces pinophilus provide insights into biotechnological applications. - Sci. Rep. 7: 490.

[22] Lindow, S. E., Leveau, J. H. (2002): Phyllosphere microbiology. - Curr. Opin. Biotechnol. 13: 238-243.

[23] Mehrotra, B. S., Kumar, D. A. (1962): A new species of Penicillium from India. Canadian Journal of Botany 40(10): 1399-1400.

[24] Murphy, J., Riley, J. P. (1962): A modified single solution method for the determination of phosphate in natural waters. - Anal Chim Acta 27: 31-36.

[25] Nautiyal, C. S. (1999): An efficient microbiological growth medium for screening phosphate solubilizing microorganisms. - FEMS Microbiol Lett. 170(1): 265-270.

[26] Nicoletti, R., De Stefano, M., De Stefano, S., Trincone, A., Marziano, F. (2004): Antagonism against Rhizoctonia solani and fungitoxic metabolite production by some Penicillium isolates. - Mycopathologia 158: 465-474.

[27] Nicoletti, R., Trincone, A. (2016): Bioactive compounds produced by strains of Penicillium and Talaromyces of marine origin. - Mar. Drugs 14: 37.

[28] Pandey, A., Das, N., Kumar, B., Rinu, K., Trivedi, P. (2008): Phosphate solubilization by Penicillium spp. isolated from soil samples of Indian Himalayan region. - World J Microbiol Biotechnol. 24: 97-102.

[29] Pitt, J. (2014): Penicillium and Talaromyces: Introduction, Penicillium. - Encyclopedia of Food Microbiology (2nd ed.): 6-13.

[30] Pol, D., Laxman, R. S., Rao, M. (2012): Purification and biochemical characterization of endoglucanase from Penicillium pinophilum MS 20. - Indian J Biochem Biophys. 49: 189-194.

[31] Pradhan, N., Sukla, L. B. (2005): Solubilization of inorganic phosphate by fungi isolated from agricultural soil. - African J Biotechnol. 5: 850-854.

[32] Premono, M. E., Moawad, A. M., Vlek, P. L. G. (1996): Effect of phosphate-solubilizing Pseudomonas putida on the growth of maize and its survival in the rhizosphere. Indonesian Journal of Crop Science 11: 13-23.

[33] Ram, H., Malik, S. S., Dhaliwal, S. S., Kumar, B., Singh, Y. (2015): Growth and productivity of wheat affected by phosphorus solubilizing fungi and phosphorus levels. Plant Soil Environ 61(3): 122-126.

[34] Requena, B. N., Jimenez, I., Toro, M., Barea, J. M. (1997): Interactions between plantgrowth-promoting rhizobacteria (PGPR), arbuscular mycorrhizal fungi and Rhizobium spp. in the rhizosphere of Anthyllis cytiisoides, a model legume for revegetation in Mediterranean semi-arid ecosystems. - New Phytol. 136: 667-677.

[35] Samson, R. A., Yilmaz, N., Houbraken, J., Spierenburg, H., Seifert, K. A., Peterson, S. W., Varga, J., Frisvad, J. C. (2011): Phylogeny and nomenclature of the genus Talaromyces and taxa accommodated in Penicillium subgenus Biverticillium. - Studies in Mycology 70: 159-183.

[36] Saxena, J., Basu, P., Jaligam, V., Chandra, S. (2013): Phosphate solubilization by a few fungal strains belonging to the genera Aspergillus and Penicillium. - Afr $\mathrm{J}$ Microbiological Res. 7: 4862-4869. 
[37] Scervino, J. M., Mesa, M. P., Monica, I. D., Recchi, M., Moreno, S., Godeas, A. (2013): Soil fungal isolates produce different organic acid patterns involved in phosphate salts solubilization. - Biol Fertil Soils 49(6): 779-779.

[38] Sembiring, M., Fauzi (2017): Bacterial and fungi phosphate solubilization effect to increase nutrient uptake and potatoes (Solanum tuberosum L.) production on Andisol Sinabung area. - J. Agron. 16(3): 131-137.

[39] Son, H. J., Park, G. T., Cha, M. S., Heo, M. S. (2006): Solubilization of insoluble inorganic phosphates by a novel salt- and $\mathrm{pH}$-tolerant Pantoea agglomerans R-42 isolated from soybean rhizosphere. - Bioresource Technol. 97(2): 204-210.

[40] Subba Rao, N. S. (1999): Soil Microbiology (Fourth Edition of Soil Microorganisms and Plant Growth). - Oxford \& IBH Publishing Co. Pvt. Ltd., New Delhi. 407.

[41] Thom, C. (1910): Cultural studies of species of Penicillium. U.S.D.A. - Bureau of Animal Industry Bulletin 118: 1-107.

[42] Venkateswarlu, B., Rao, A. V., Raina, P. (1984): Evaluation of phosphorus solubilization by microorganisms isolated from arid soil. - J. Ind. Soc. Soil Sci. 23: 273-277.

[43] Visser, E. M., Falkoski, D. L., de Almeida, M. N., Maitan-Alfenas, G. P., Guimarães, V. M. (2013): Production and application of an enzyme blend from Chrysoporthe cubensis and Penicillium pinophilum with potential for hydrolysis of sugarcane bagasse. Bioresource Technol. 144: 587-594.

[44] Wang, M. H., Li, X. M., Li, C. S., Ji, N. Y., Wang, B. G. (2013): Secondary metabolites from Penicillium pinophilum SD-272, a marine sediment-derived fungus. - Mar. Drugs. 11: 2230-2238.

[45] Wani, Z. A., Mirza, D. N., Arora, P., Riyaz-Ul-Hassan, S. (2016): Molecular phylogeny, diversity, community structure, and plant growth promoting properties of fungal endophytes associated with the corms of saffron plant: An insight into the microbiome of Crocus sativus Linn. - Fungal Biol. 120(12): 1509-1524.

[46] Watanabe, T. (2010): Pictorial atlas of soil and seed fungi morphologies of cultured fungi and Key to species, Third Edition. - CRC press, Florida.

[47] Xian, L., Wang, F., Luo, X., Feng, Y-L., Feng, J-X. (2015): Purification and characterization of a highly efficient calcium-independent alpha-amylase from Talaromyces pinophilus 1-95. - PLoS ONE 10(3): e0121531.

[48] Yao, Y. Q., Lan, F., Qiao, Y. M., Wei, J. G., Huang, R. S., Li, L. B. (2017): Endophytic fungi harbored in the root of Sophora tonkinensis Gapnep: diversity and biocontrol potential against phytopathogens. - Microbiology Open: 1-17.

[49] Zhang, Y., Chen, F-S., Wu, X-Q., Luan, F-G., Zang, L-P., Fang, X-M., Wan, S-Z., Hu, $\mathrm{X}-\mathrm{F}$., Ye, J-R. (2018): Isolation and characterization of two phosphate solubilizing fungi from rhizosphere soils of moso bamboo and their functional capacities when exposed to different phosphorus sources and pH environment. - PLoS ONE 13(7): e0199625. 